${ }^{3}$ Dockray GJ, Vaillant C, Hopkins CR. Biosynthetic relationships of big and little gastrins. Nature 1978;273:770-2.

4 Dockray GJ. Brain gut peptides. Viewpoints on digestive diseases. 1981;13:5-8.

${ }^{5}$ Kreiger DT, Martin JB. Brain peptides. First of two parts. $N$ Engl J Med 1981;304:876-85.
${ }^{6}$ Kreiger DT, Martin JB. Brain peptides. Second of two parts. $N$ Engl J Med 1981;304:944-51.

Correspondence to Dr N Linder, Department of Pediatrics, Hadassah Medical Centre, POB 12000, Jerusalem 91120, Israel.

Accepted 27 July 1988

\title{
Effects of ethamsylate on cerebral blood flow velocity in premature babies
}

\author{
J M RENNIE AND P K L LAM \\ Department of Paediatrics, University of Cambridge
}

SUMMARY Cerebral blood flow velocity and cardiac output were measured with ultrasound before and 30 minutes after the administration of ethamsylate in a double blind placebo controlled study of 19 very low birthweight infants. No differences were found before or after treatment in either group.

Ethamsylate (diethylammonium 2,5-dihydroxybenzenesulphonate) is a non-steroidal drug that reduces bleeding from small vessels. The results of a double blind multicentre study showed that there were fewer severe periventricular haemorrhages among the survivors of a group of very low birthweight infants treated with this drug shortly after birth. ${ }^{1}$ The mode of action remains to be clearly elucidated but experimental evidence shows an inhibition of the products of the prostaglandin pathway. ${ }^{2}$ A group of very low birthweight infants with respiratory distress syndrome treated with ethamsylate had lower serum concentrations of immunoreactive prostacyclin metabolite than an untreated control group, ${ }^{3}$ and one interpretation was that the drug limited prostacyclin release from ischaemic brain, perhaps preventing bleeding secondary to the presence of this potent vasodilating and platelet disaggregating substance.

Prostaglandins are known to play a part in cerebral blood flow. Indomethacin inhibits prostaglandin production although at a different enzymatic point than that thought to be affected by ethamsylate. Studies in animals, adult humans, and babies attest to the reduction in cerebral blood flow velocity after treatment with indomethacin. ${ }^{4}$ Although inhibition of the prostaglandins produced by metabolism of arachidonic acid are not as complete after treatment with ethamsylate as after treatment with indomethacin, it seems plausible that this drug may also reduce cerebral blood flow velocity in the newborn. Periventricular haemorrhages develop early in postnatal life in most infants, therefore a common approach to prevention entails prophylactic administration of the drug to a cohort of babies defined as 'high risk'. Sixty per cent of very low birthweight infants will be given treatment for a condition that they will never develop if this approach is adopted; proposed agents therefore need to be fully investigated.

\section{Patients and methods}

Nineteen very low birthweight infants admitted to the Cambridge neonatal intensive care unit who did not have periventricular haemorrhages were studied at a postnatal age of less than 12 hours. Mean (SD) birth weight was 1105 (265) and mean gestational age 28 weeks (range 26-31). Approval for the investigation was granted by the ethical committee of Addenbrooke's Hospital. Measurements of cerebral blood flow velocity and cardiac output were made before and 30 minutes after administration of a solution containing either ethamsylate or saline. Infants were treated with $0.1 \mathrm{ml} / \mathrm{kg}$ of solution that contained either $12.5 \mathrm{mg} / \mathrm{kg}$ of ethamsylate, or saline alone. The solution was prepared in identical vials by the manufacturers who held the identification code until the end of the study.

Measurement of cerebral blood flow velocity and cardiac output were made by duplex Doppler ultrasound (ATL Mk 600). Doppler signals from the anterior cerebral artery were identified using the real time image and the Fourier transform of the frequency shift was sampled using an Apple IIe microcomputer. This was used to estimate time averaged mean velocity from several consecutive cardiac cycles and also used to calculate the Pourcelot resistance index. ${ }^{5}$ This was expressed as the peak systolic velocity minus the diastolic velocity divided by the peak systolic velocity. The same computa- 
tion, including an angle correction where necessary, was performed for an ascending aortic Doppler sample. This velocity figure, together with an estimate of the aortic size from the internal edge diameter measured by $M$ mode echocardiography, was used to calculate the cardiac output.

Results were analysed by non-parametric statistical tests using the Statistical Package for the Social Sciences. The sign test and the Wilcoxon rank sum test were used to compare pairs of results, and unpaired results were compared by the MannWhitney U test.

\section{Results}

There was no difference in cardiac output, velocity of blood flow in the cerebral arteries, or the Pourcelot resistance index between the two sets of observations in either the treated or placebo group (table). By chance the ethamsylate treated group had a slightly lower median velocity than the control babies and the velocity in the treated group is significantly lower than in the control group at 30 minutes. This is unlikely to reflect an effect of the drug because the Wilcoxon and sign tests of the paired results are not significant.

The tendency to lower cerebral blood flow velocity in this group was not explained and was not followed by more intraventricular haemorrhages (one in each group).

\section{Discussion}

In this group of premature babies ethamsylate had no effect on cerebral blood flow velocity, Pourcelot index, or cardiac output.

Reduction of cerebral blood flow after treatment with indomethacin occurs after a few minutes, and one interpretation is that these effects cannot therefore be due to prostaglandin inhibition, which takes at least $\mathbf{3 0}$ minutes and perhaps as long as two hours to occur. ${ }^{6}$ An effect mediated by some factor associated with the structure of indomethacin would also explain the observations that a reduction in cerebral blood flow velocity has not been seen with other prostaglandin synthetase inhibitors such as aspirin, and that one hour after the administration of identical doses of indomethacin given at different rates only those infants who received a rapidly administered dose had reduced cerebral blood flow velocity. Aspirin is a more potent inhibitor of prostaglandin synthesis than ethamsylate, and prolongs the bleeding time in the same way as indomethacin, an effect not seen in preterm babies treated with ethamsylate. ${ }^{3}$

The concern about possible ischaemic damage caused by a reduction in cerebral blood flow after rapid administration of indomethacin does not seem to apply to ethamsylate. It may be that a reduction in the incidence of neurodevelopmental handicap will be associated with fewer grade 2 and 3 periventricular haemorrhages in the survivors treated with ethamsylate, but meanwhile it would seem a safe choice for those who wish to use pharmacological prophylaxis in the nursery.

We thank Children Nationwide, the Trustees of Addenbrooke's Hospital, and the East Anglian Regional Area Health Authority for financial support. PL is a British Council scholar.

\section{References}

1 Benson JWT, Drayton MR, Hayward C, et al. Multicentre trial of ethamsylate for prevention of periventricular haemorrhage in very low birthweight infants. Lancet 1986;ii:1297-1300.

2 Kovacs L, Falkay G. Ethamsylate as inhibitor of prostacyclin synthesis in pregnant human myometrium. Experientia 1981;37:1182-3.

3 Rennie JM, Doyle J, Cooke RWI. Ethamsylate reduces immunoreactive prostacyclin metabolite in low birthweight infants with RDS: possible mode of prevention of intraventricular haemorrhage. Early Hum Dev 1986;14:239-44.

4 Evans DH, Levene MI, Archer LNJ. The effect of indomethacin on cerebral blood flow velocity in premature infants. Dev Med Child Neurol 1987;20:776-82.

5 Drayton MR, Skidmore R. Vasoactivity of the major intracranial arteries in newborn infants. Arch Dis Child 1986;62:230-46.

6 Rennie JM, Doyle J, Cooke RWI. Early administration of indomethacin to preterm infants. Arch Dis Child 1986;61:233-8.

Correspondence to Dr JM Rennie, Department of Paediatrics, Level 8, Addenbrooke's Hosptial, Hills Road, Cambridge CB2 2QQ.

Accepted 26 September 1988

Table Cerebral blood flow velocity. Pourcelot index, and cardiac output in the two groups. Values are given as median (interquartile range)

\begin{tabular}{lllllll}
\hline & \multicolumn{2}{l}{ Group given ethamsylate } & & \multicolumn{2}{l}{ Group given placebo } \\
\cline { 2 - 3 } & Before treatment & After treatment & & Before treatment & After treatment \\
\hline Cerebral blood flow velocity $(\mathrm{cm} / \mathrm{s})$ & $2 \cdot 83(2 \cdot 34-3 \cdot 5)$ & $2 \cdot 18(1 \cdot 95-3 \cdot 15)^{*}$ & & $3 \cdot 55(2 \cdot 6-5 \cdot 75)$ & $4 \cdot 3(3 \cdot 4-5 \cdot 2)^{*}$ \\
Pourcelot index & $0 \cdot 93(0 \cdot 77-0 \cdot 98)$ & $0 \cdot 88(0 \cdot 81-1 \cdot 0)$ & & $0 \cdot 92(0 \cdot 7-0 \cdot 98)$ & $0 \cdot 79(0 \cdot 79-0 \cdot 9)$ \\
Cardiac output $(\mathrm{ml} / \mathrm{kg} / \mathrm{min})$ & $201(146-220)$ & $144(130-193)$ & & $158(133-253)$ & $138(127-227)$ \\
\hline
\end{tabular}

${ }^{*} \mathrm{p}<0.05$, Mann-Whitney $U$ test. 